This article has been scanned by iThenticat No plagiarism detected

Volume 3, Issue 5, October 2021

p. 347-357

\title{
ABU NAWAS AL-HASSAN BIN HANI, BETWEEN AL-AKKAD AND AL-NUWEHI, AN APPROACH TO THE REPRESENTATION OF THE PSYCHOLOGICAL METHOD
}

http://dx.doi.org/10.47832/2757-5403.5-3.30

\section{Nassima BERRAG 1 \& Rima BERAGRAG 2}

\begin{abstract}
:
Modern Arab theory is based on the evocation of contextual occidental approaches that are out of text.

Here, signs of critical modernity began in the reading of traditional Arabic texts, and one of the most important texts around which the readings revolved was the text of Abu Nawas, symbol of textual modernity for Arabs, as demonstrated by Adonis.

This research paper seeks to find the balance between the two Arab readings that invoked the psychological approach to enlighten the text of Abu Nawas, the reading of Abbas Mahmoud Al-Akkad marked "Abu Nawas Al-Hassan Bin Hani", which is famous for studying biography and genius in which the personality key was followed as a tool from which it can penetrate into its depth and thought, and the study of Muhammad Al-Nohi's "The Psychology of Abu Nawas", which is a unique modern critic in his critical view, began to define literature as "the supreme fruit of the experiences of human life", his study preceded Akkad's study by nine months, and both were in the same year 1953, This justifies the legitimacy of the balance between them on the one hand, and calls for an examination of the effects of comparison within the Arab critical theory, which has been influenced by Western theories, and which are given by the Freudian incubator. The comparison that the intervention intends to make is descriptive speech (meta critical).

As for the problem posed by the research paper, consists in: What are the paradoxes that a single psychological approach poses to the multiplicity of readers and to the unity of the method?

Al-Akkad relied on the dictum of narcissism to decompose Abu Nawas's personality, and psychologists took this word (narcissism) to denote the

\footnotetext{
${ }^{1}$ Dr. , Mohamed lamine debbaghine. Sétif 2 University , Algeria, Bnassima2009@yahoo.fr, https://orcid.org/0000-0002-1883-4009

${ }^{2}$ Dr. , Mohamed lamine debbaghine. Sétif 2 University, Algeria, salem.aziza@gmail.com, https://orcid.org/0000-0003-4485-588X
}

Copyright (C) Published by IJHER Journal, www.ijherjournal.com Rimar Academy, Fatih, Istanbul, 34093 Turkey

All rights reserved 
associated bodily discomfort and sexual lust, and to signify a person's infatuation with his body and desire for sexual lust, he feels like an image of himself, which completes his composition and all the imperfections he feels, according to Shawqi Deif.

Based on the complex of narcissism, Al-Akkad explained the manifestations of the complex in what was called Autoimmune and selfenvy, while Al-Noaihi went to the complex of Oedipus and inferred it with textual evidence under the name: the sexual replacement of a mother with wine and the sublimation expressed in the poetic work.

We note here that the Arab critical theory stopped with these two writers, and that it did not use the developments of the psychological structural approach as presented by Jacque Lacan, his works not yet being translated into Arabic .

Key words: Abu Nawas, Al-Akkad, Al-Noaihi, Psychological Method, Critical Theory.

$$
\begin{aligned}
& \text { أبو نواس الحسن بن هانئ بين العقاد والنويهي، مقاربة في تمثُّل المنهج النفسي } \\
& \text { نسيمة برقة براق } 3
\end{aligned}
$$

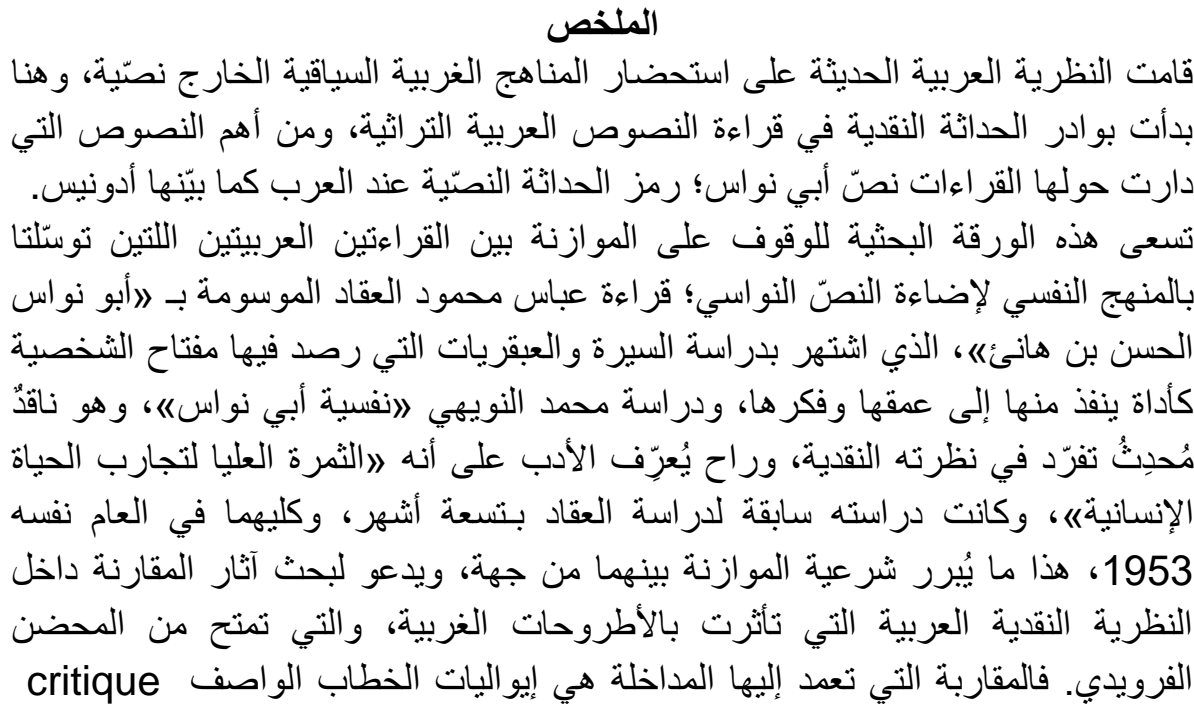

$$
\begin{aligned}
& \text { Méta } \\
& \text { أمّا الإثكالية التي تطرحها الورقة البحثية هي:ما المفارقات التي بطرحها المنهج النفسي }
\end{aligned}
$$

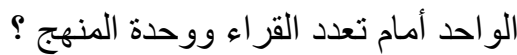

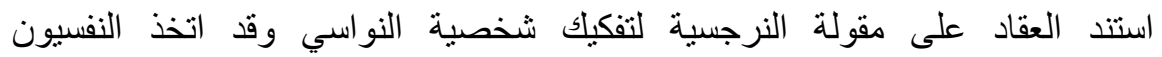

$$
\begin{aligned}
& \text { ((narcissisme)) }
\end{aligned}
$$

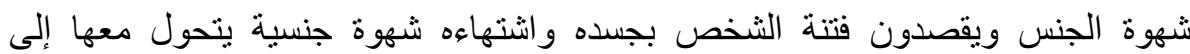

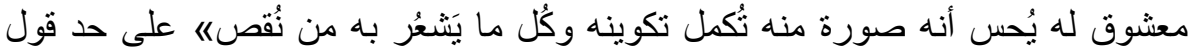

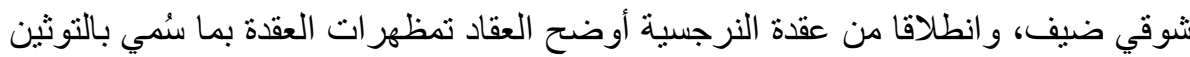




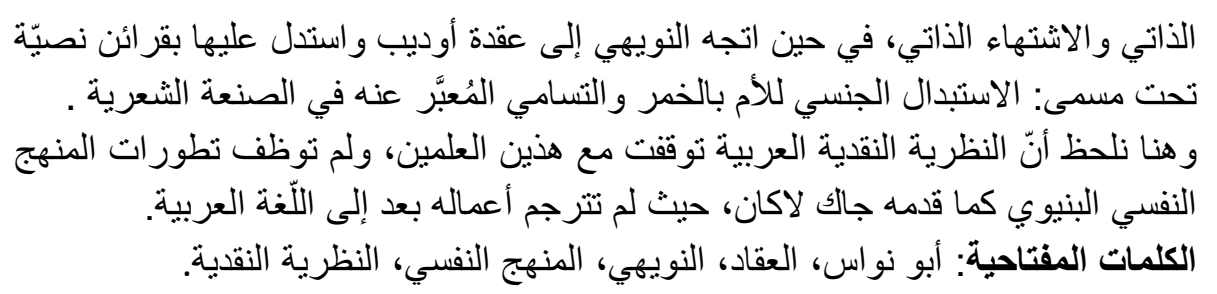

المقدمة:

في سياق تتبع تطور النظرية النقية العربية الحديثة، نلمح نوجُها إلى الاستعانة بالمناهج الغربية السياقية (الخارج نصية)

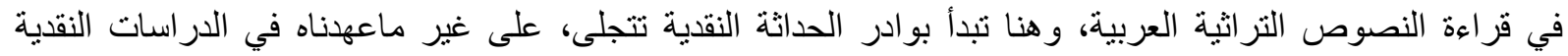

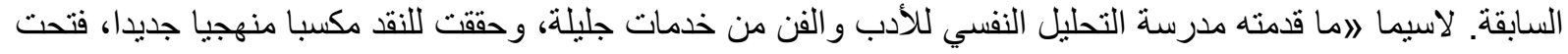

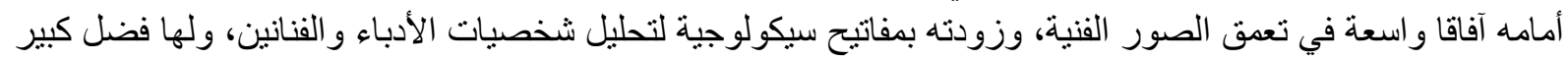

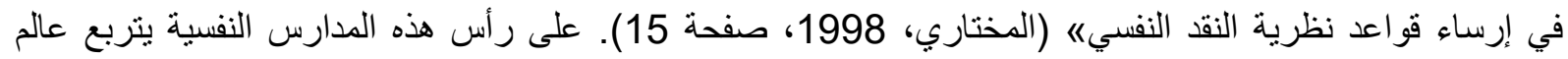

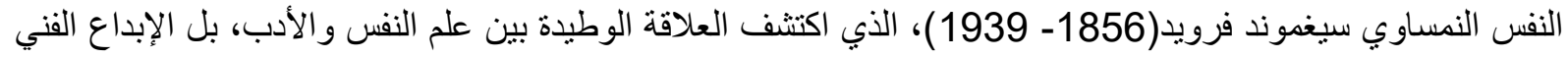

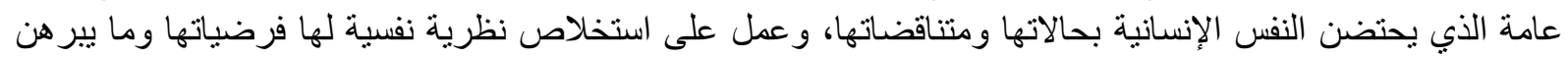

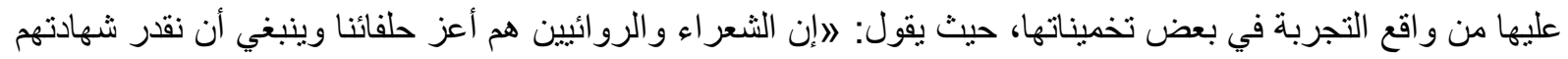

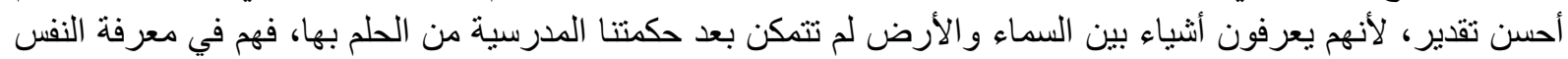

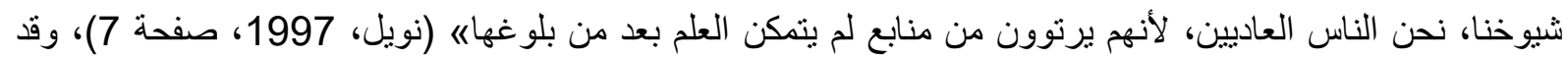

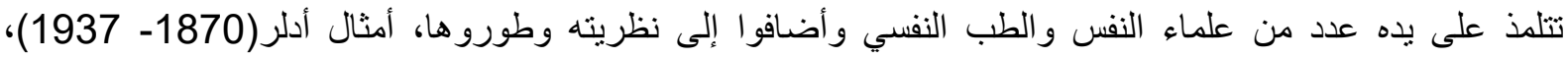

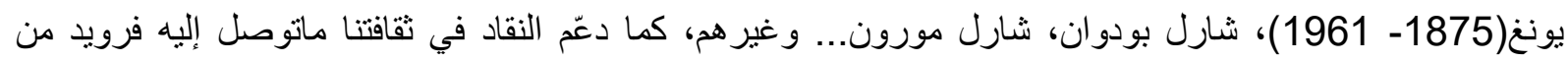

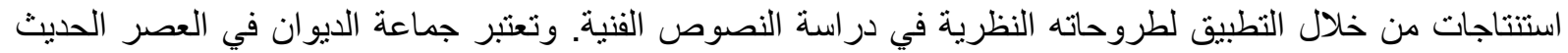

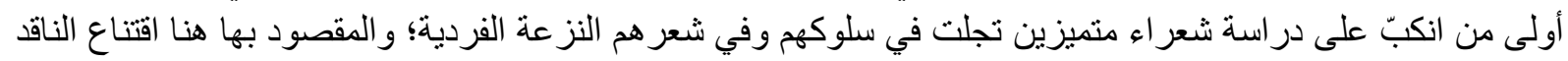

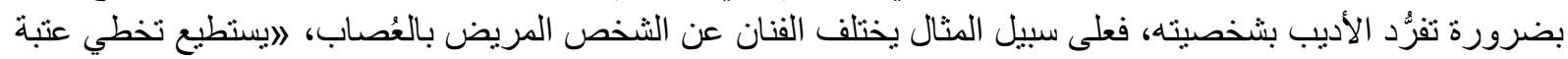

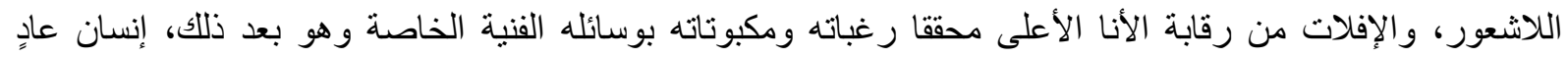

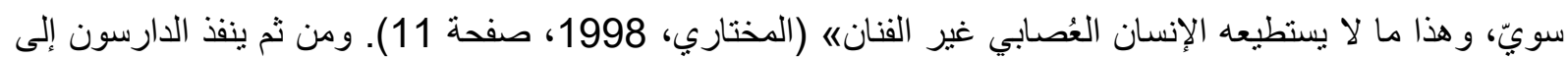

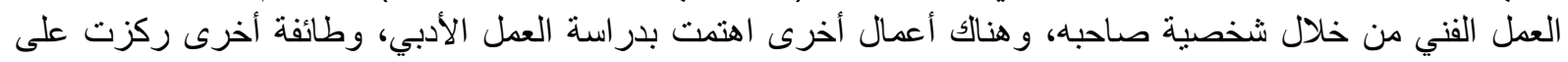

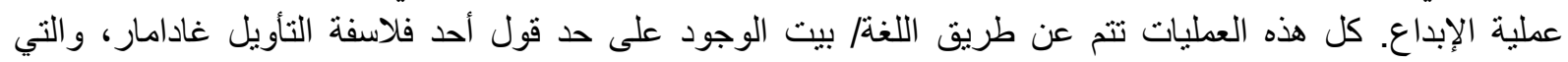

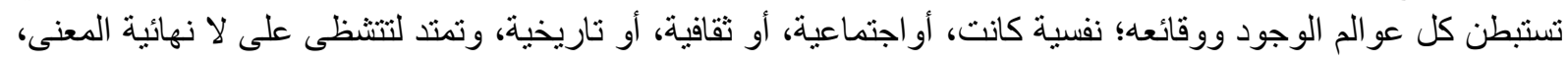

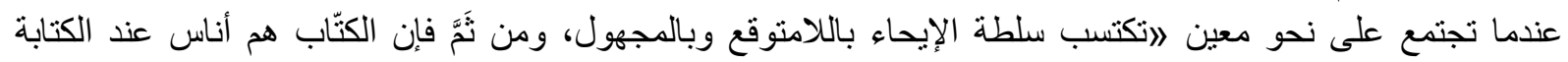

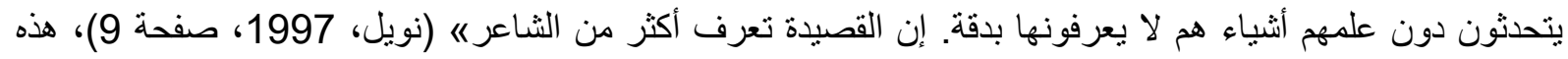

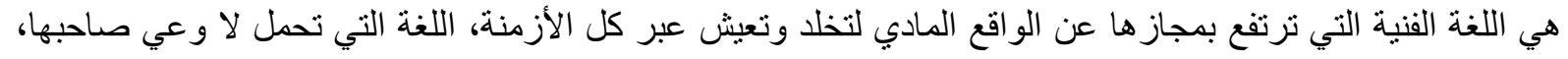

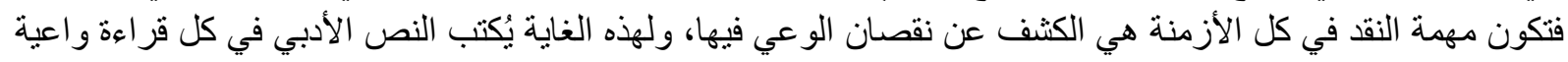
تتغيَّا مكنوناته لتكثنف إمكاناته وطاقاتها

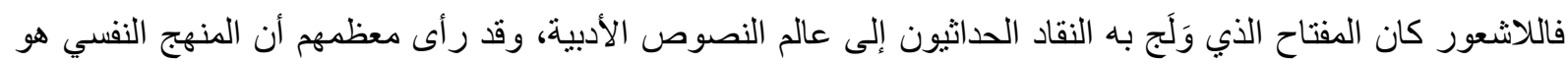

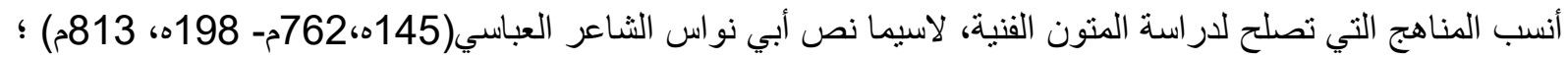

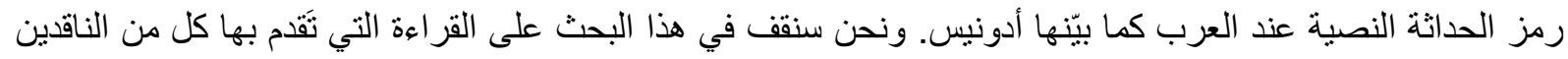

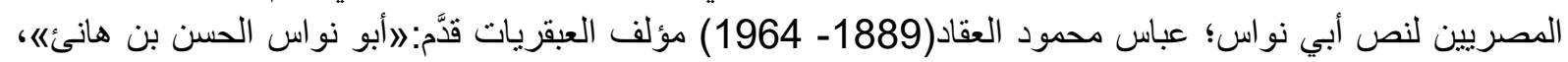

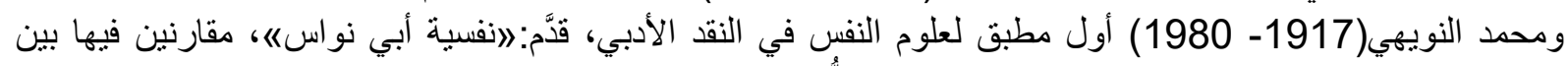

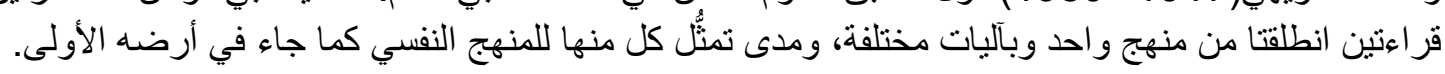

أولا: المقاربة النفسية عند العقاد

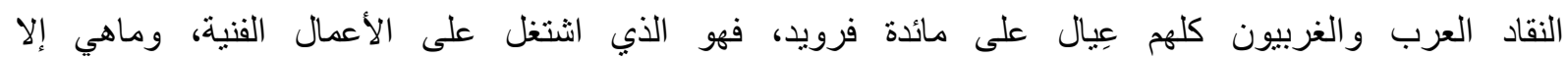

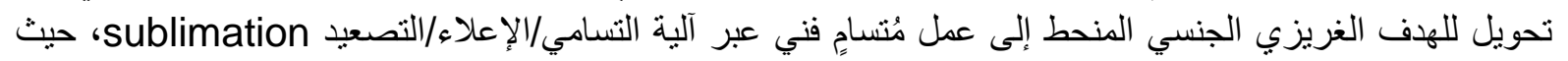
》ا افترض فرويد هذه العملية لتبيان النشاطات الإنسانية الني لا صلة ظاهرية لهية لها مع الجنسية، ولكنها تستقي مددها من قوة 
النزوة الجنسية، ولقد أطلق فرويد أساساً وصف التسامي على النشاط الفني والاستقصاء الذهني «(ج.ب.بونتاليس،

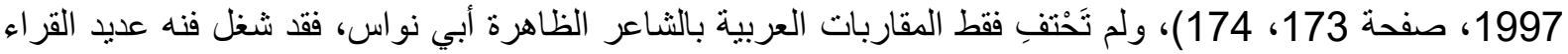
الغرب و المترجمين؛ باللغة الإنجليزية و الفرنسية نذكر منها:

كتاب «abu nawas in life end legend بقلم ويليام هارولد انجر امز (1973-1897)، هو ضابط بريطاني،

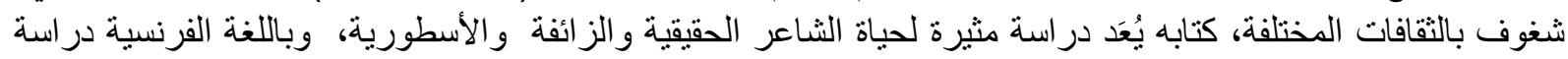
جمال الدين بن شيخ كتب عن أبي نو اس خمرياته: " Jamel- Eddine Benchikh: poésies bachiques هd’Abu Nuwas:thémes et personnages. و العقاد الثخصية العبقرية ألف عديد الأعمال، في السير الغيرية، وحاول فيها الكثف عن مفتاح الثناح الثخصية، حيث يعتبره الأداة الصغيرة التي تفتح لنا أبو ابها، وتنفذ بنا وراء أسوار ها وجدر النها، (ولكل شخصية إنسانية مفتاح يسهل الوصنية الوصول إليه

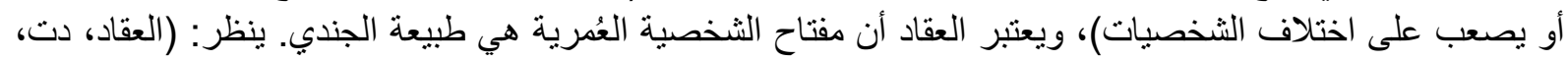

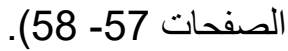

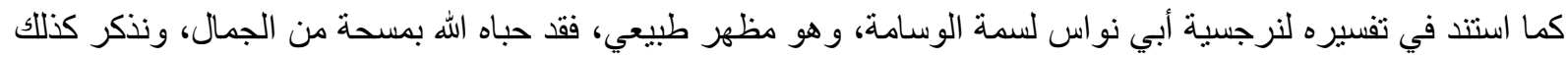

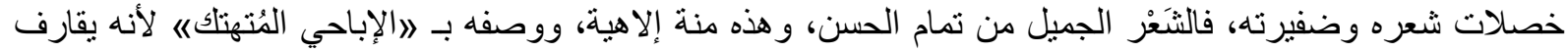

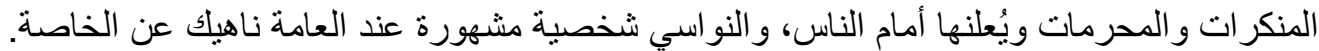

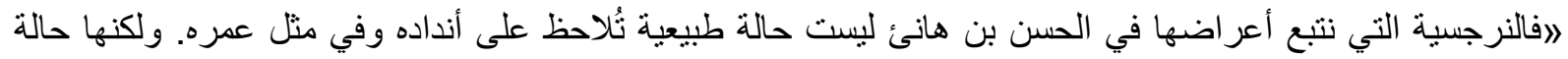
منحرفة وُلد ببعض أعر اضها وجاءت الأعر اض الأخرى من البيت و المجتمع و العصر الذي نشأ فيها (العقاد، أبو نواس اسل

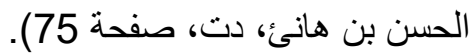

مصادر نرجسية أبي نواس:

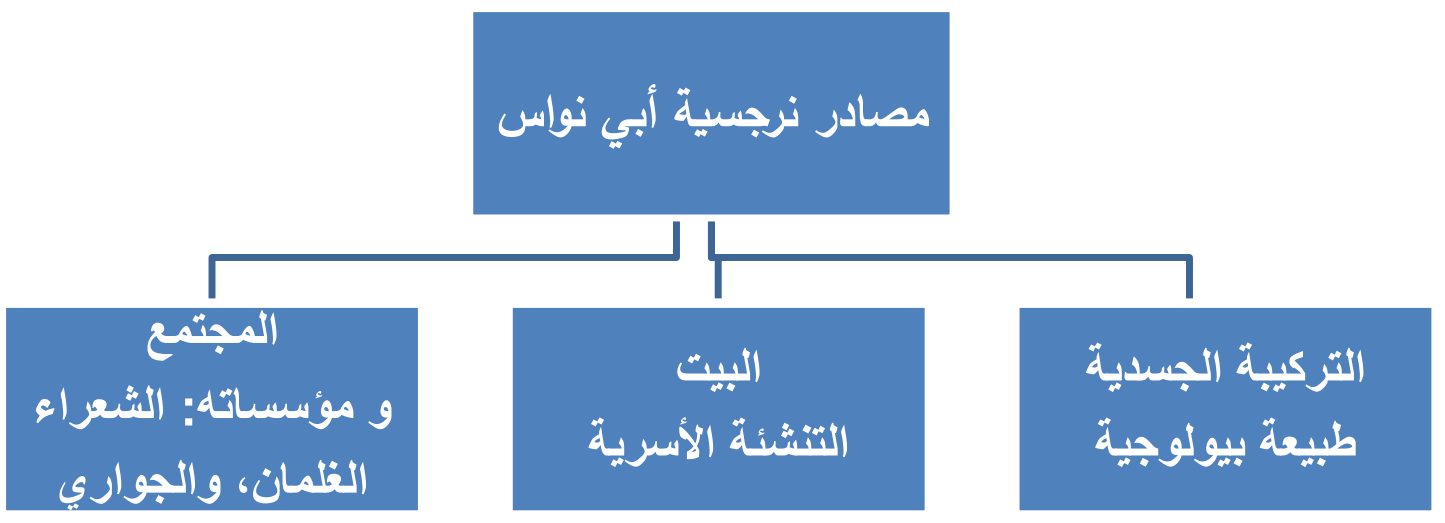

و علاوة على العقدة الأساسية التي فسر على أساسها العقاد شعر أبي نواس يضيف مركب النقص قائلا: اديوان الثناعر

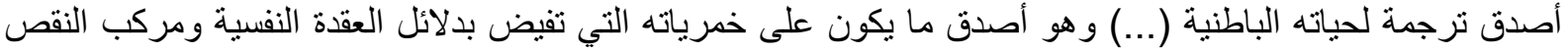

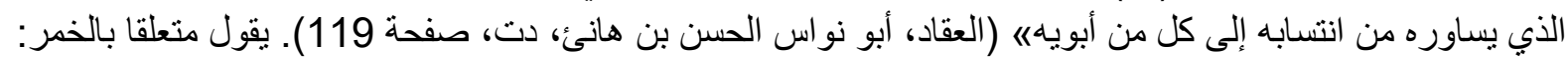

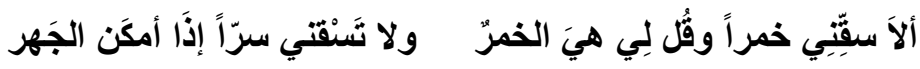

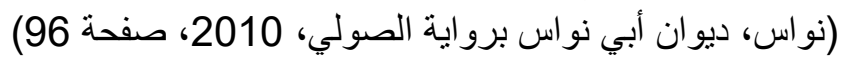

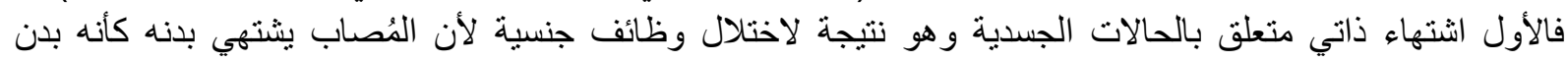

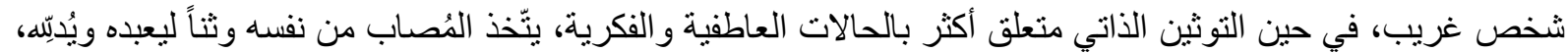

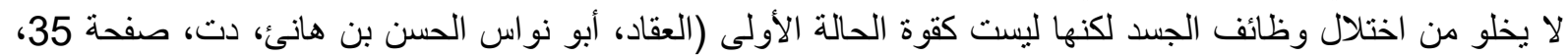

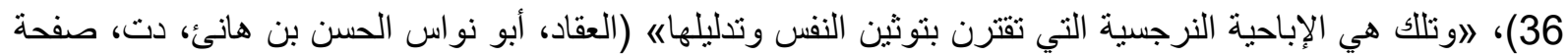


وقد اقترنت لغة العقاد في تحليله لنرجسية أبي نواس بمجموعة من الاصطلاحات رآها لازمة تنكرر في شعر أبي نواس، وهي بمثابة الخيط الناظم لخطابه، يمكن إجمالها فيما يلي:

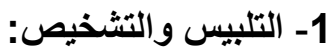
تغزل أبو نو اس في غلام ألثغ، ألبس نفسه على هذا الغلام الذي كانت الثغته بالسين ،غير أن أبا نواس لثغتنه بالراء يقول

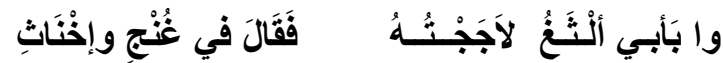

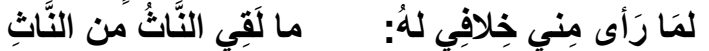

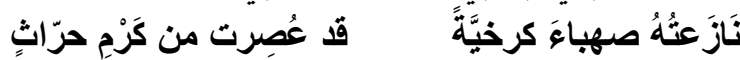

(نواس، ديوان أبي نواس برواية الصولي، 2010، صفحة 77 مرنة

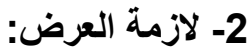

نتنقل إلى لازمة العرض التي تشمل الإظهار بجميع درجاته، إذ ارتبطت بالأعضاء الجسدية والثواغل الإل الحسية يصل فيها

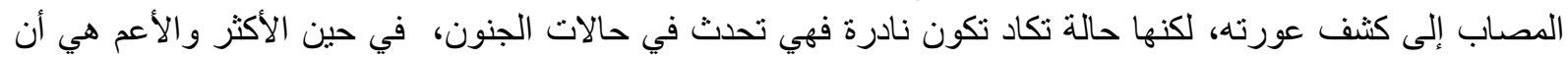

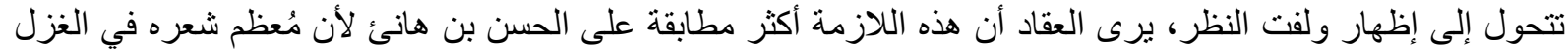

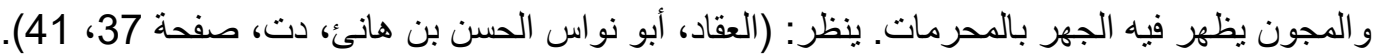
بمعنى أن النو اس يستمتع بمقارفة المحرمات لكن تزداد هذه المتعة بمقار المخاد المخالفة المعارضة.

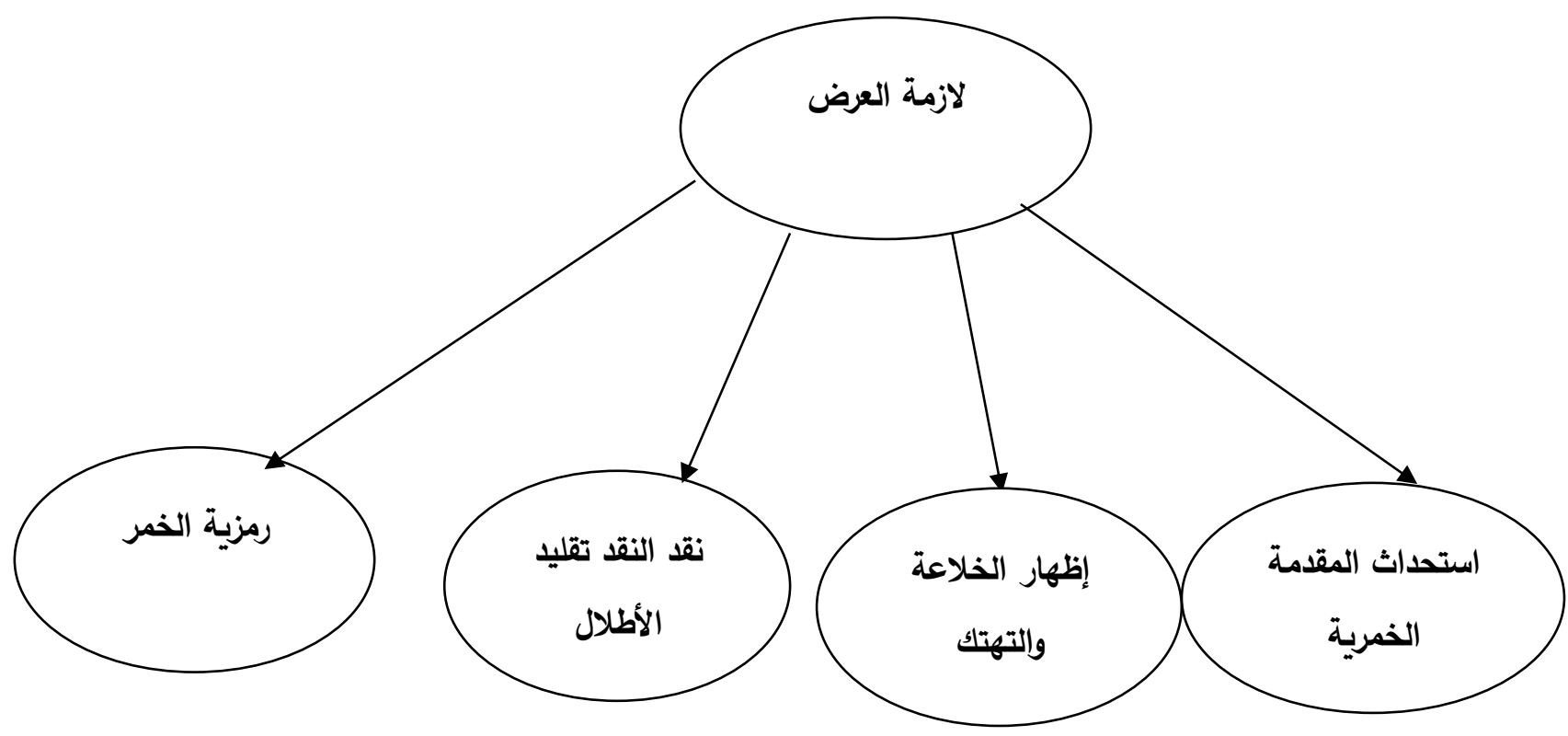

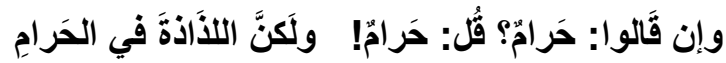

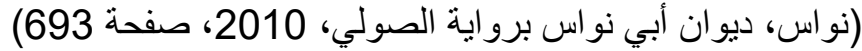

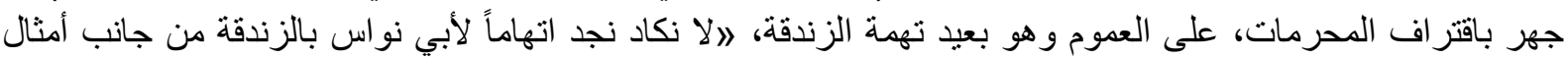

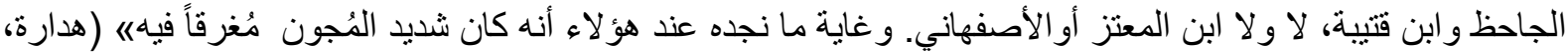
1963، صفحة 253) ـ وفي مجونه هذا نراه ينحدث عن علاقة أخرى له فهو يقول:

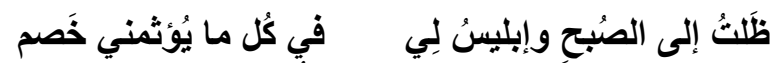
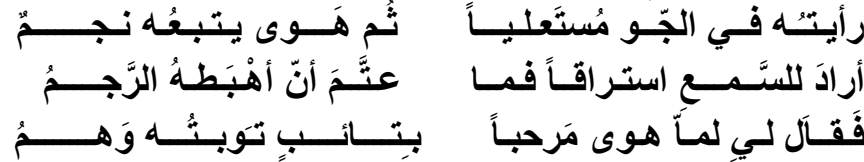

(نواس، ديوان أبي نواس برو اية الصولي، 2010، صفحة 224) 
امن منافع إبليس في مجون أبي نواس أن يكفل لله وجاهة التمبيز بالخمرة التي هو كفؤ لها دون عذالهه (العقاد، أبو نواس

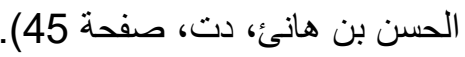

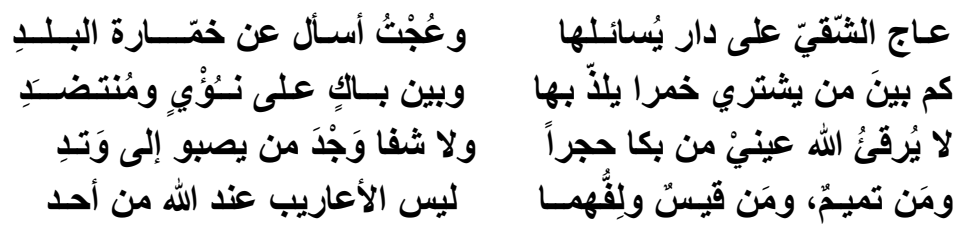

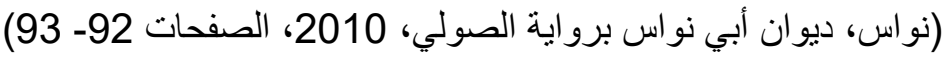

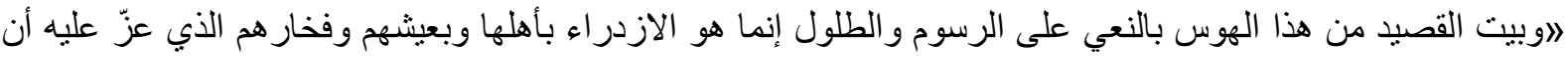
يُجاريهم فيهه (العقاد، أبو نو اس الحسن بن هانئ، دت، صنئ صنحة 120).

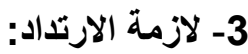

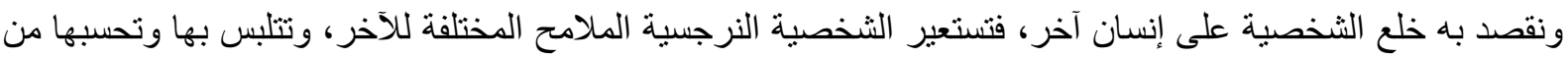

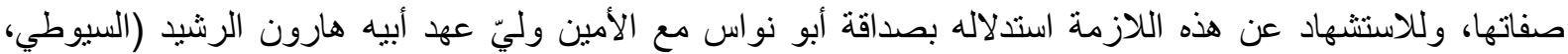

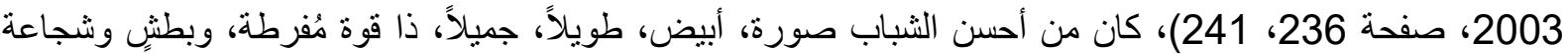

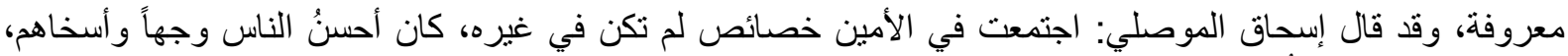

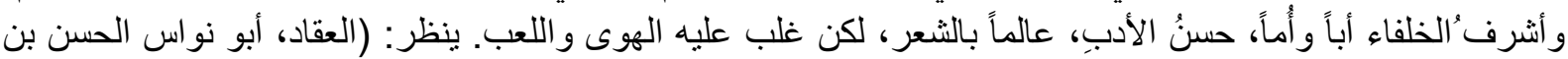

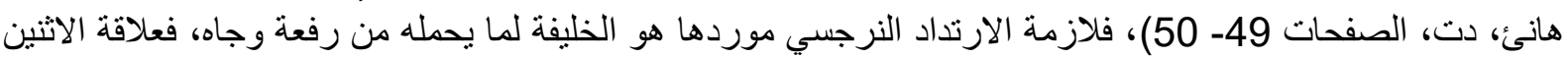
كانت علاقة عانثق ومعشوق، يظهر في قوله:

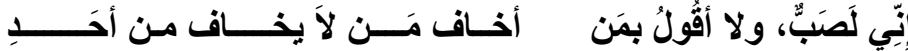

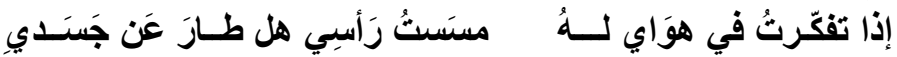

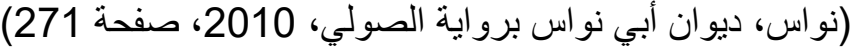

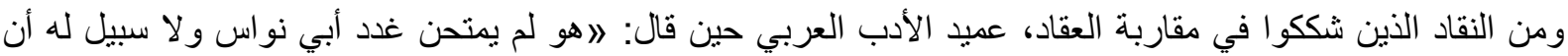

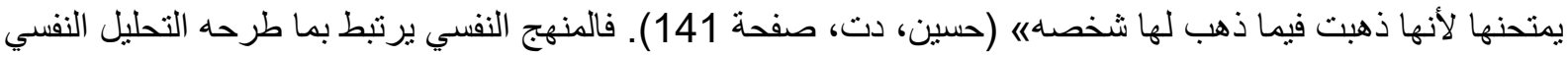
من أدوات، ويحتاج إلى فحص عياني و إلى اختبارات موضعية، حتى إذا تحققت كل الثروط في الحالة المعايَنة يكون التشخيص سليما.

ثانيا: نفسية أبي نواس من منظور محمد النويهي

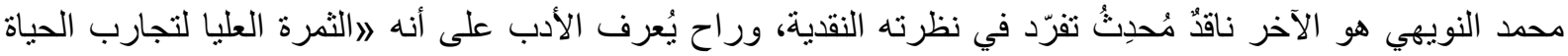

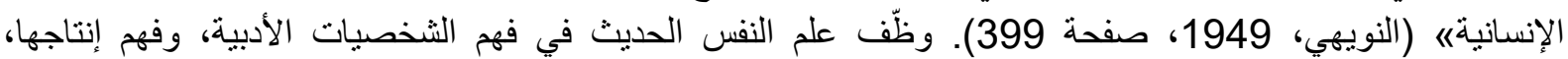

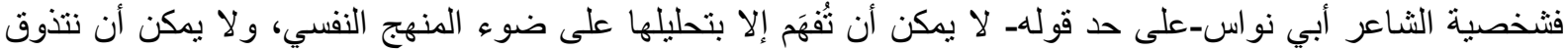
شعره تذوقا فنيا عميقا إلا بإدر الك الخصائص و المظاهر السلوكية كما تناولتها وفسرنها نظريات علم النفس الحديث.

المرجعية المعرفية في تعليل النويهي لنص أبي نواس:

استند النويهي على عقدة أوديب Complexe d'oedipe في التحليل والدراسة، وهي/الجملة المنظمة من رغبات الحب والعداء التي يشعر بها الطفل تجاه والديه، نظهر هذه العقدة في شكلها المسمى إيجابيا كما في قصة أوديب- الملك الكي

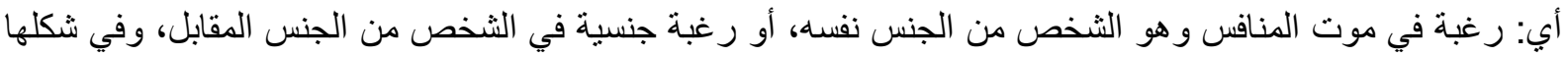
السلبي تأخذ منحى مقلوبا أي: حب للو الد من الجنس نفسه وحقد حسود على الو الد من الجنس المقابل. تبلغ عقدة أوديب

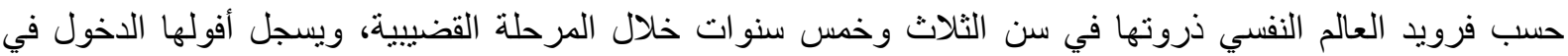

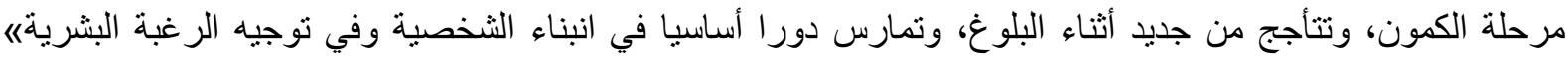

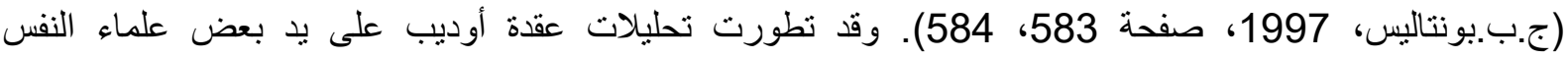

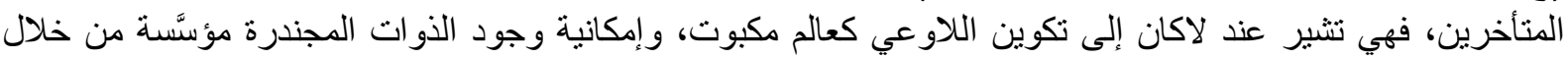


الدخول إلى النظام الرمزي، وتثثير عند كرستيفا وكودوراو وكتاب آخرون إلى تكوين بعض الأساليب الخاصة من الذكورة والأنوثة. ينظر: (باركر ، 2018، 2018، صفحة 255)

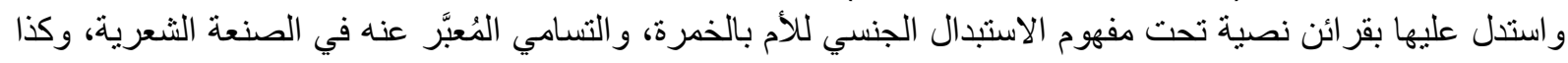
مفهوم التمركز القضيبي. وهي مفاهيم تندرج ضمن مفهوم أكبر هو الثذوذ الجنسي الذي ترنكز عليه عقدة أوديب التي طرحها فرويد في نظريته النفسية. هذا إضافة إلى عامل آخر هو خرقه لقو انين المجتمع و التمرد عليه بجر أة، و إفساده للغلمان الذين كان يهيم بهر، وكان يجهر

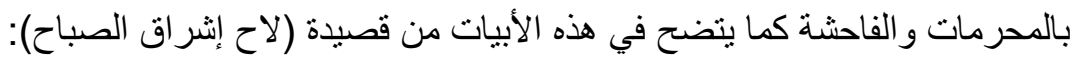

$$
\text { هذه الطيب اللأات ما كاتـ }
$$

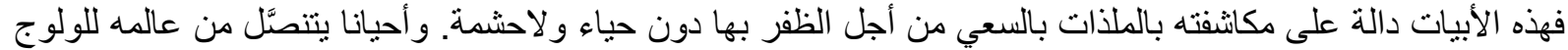

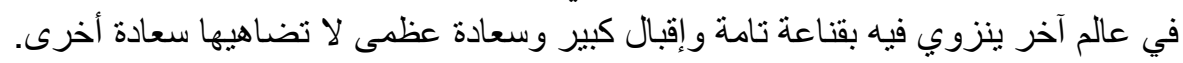

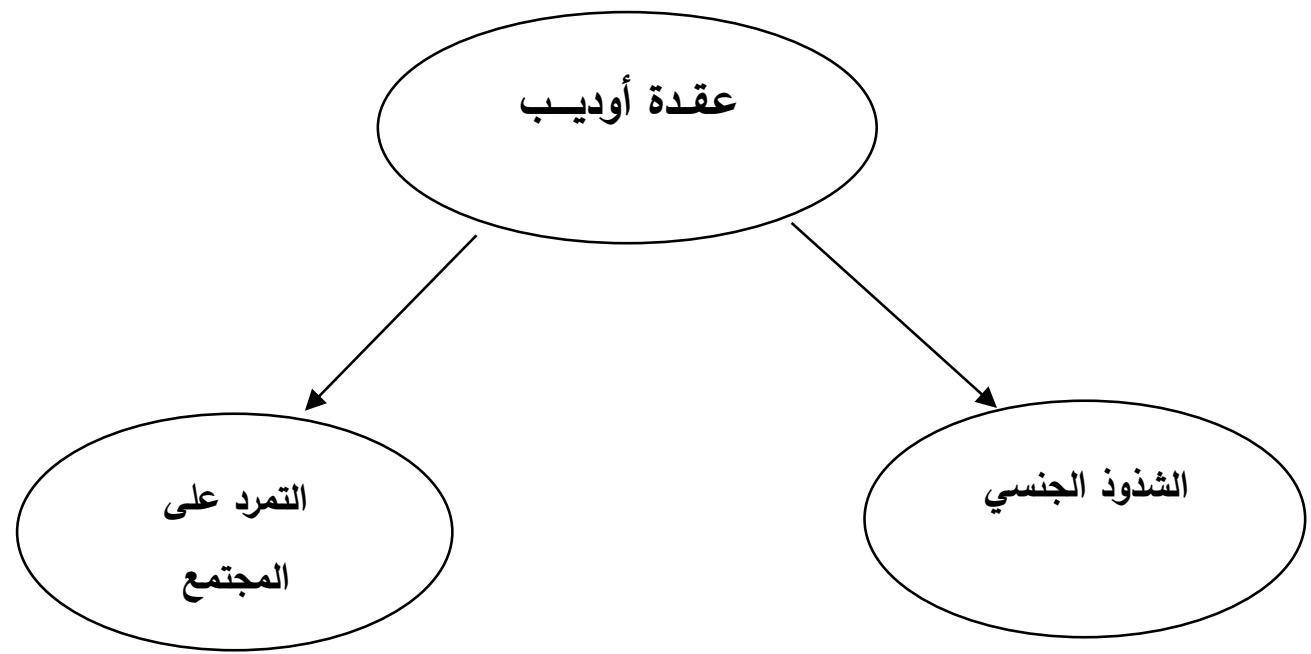

1- دوافع تثُكُل الثذوذ الجنسي عند أبي نواس:

يتمظهر الثذوذ الجنسي في مجموعة من السلوكات غير طبيعية، نفصل فيها بعد التعرف على العوامل التي تسببت في

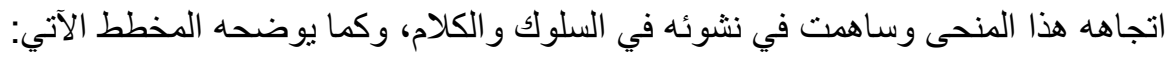

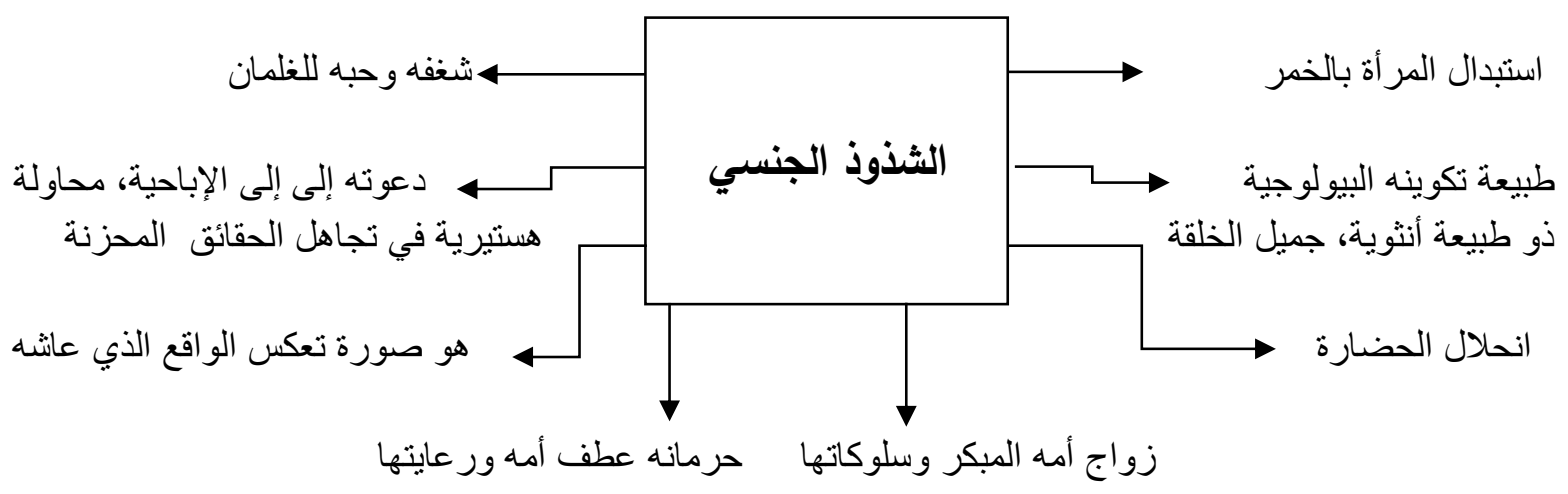

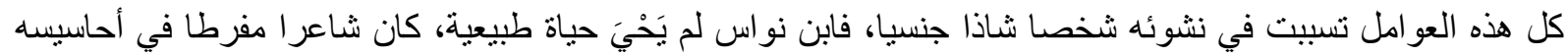

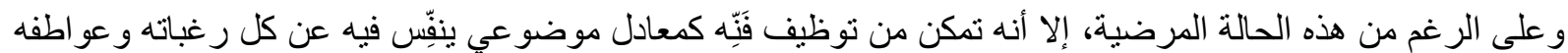

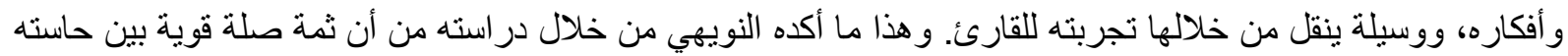

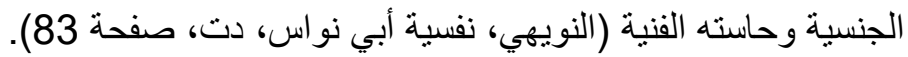


هذه مفاهيم اصطلح عليها علم التحليل النفسي ولها علاقة وثيقة برابطة الأم كما نجدها في منظومة علم النفس الفرويدية، فهي اصطلاحات تشرح العقد النفسية التي عانى منها أبو نو اس في حياته، و التي تتمثل في:

1-2 مفهوم الاستبدال الجنسي Fétichisme Sexuel:

المقصود به اتخاذ بعض المنحرفين أثياء مادية يهيمون بها هياما جنسيا شديدا، وتثير فيهم شهوة المواقعة أو(اللقاء

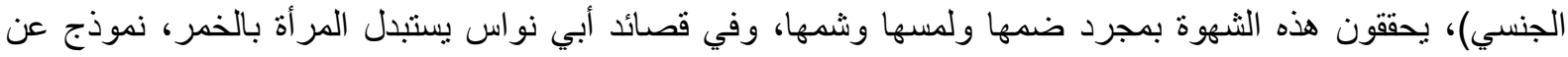

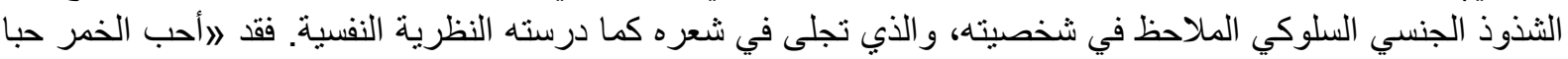

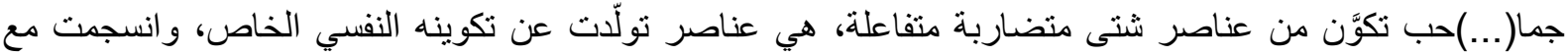

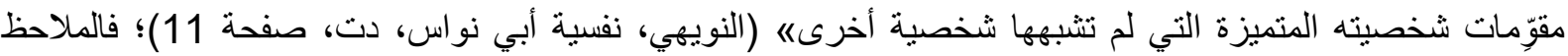

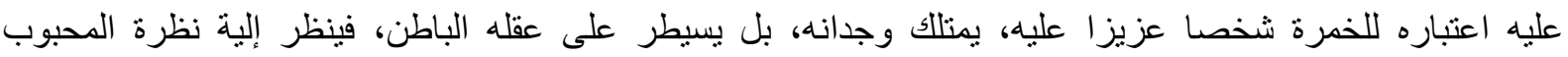

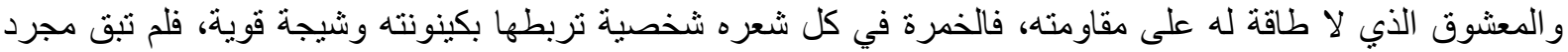

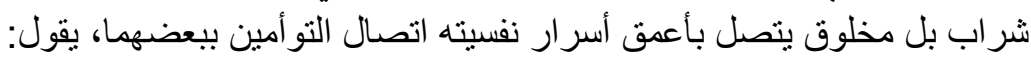
(نواس، ديو ان أبي نو اس برواية الصولي، رولئ 2010، صفحة 82)

\section{عاذلي في المدام غير نصيح لا تلمني على شقيقة روحي}

ويصف تعلقه بها و عطوف نفسها إليها عطوفا مقيما لا ينتني بقوله:

$$
\begin{aligned}
& \text { يجنح القلب إليــها في الهوى أي جنوح }
\end{aligned}
$$

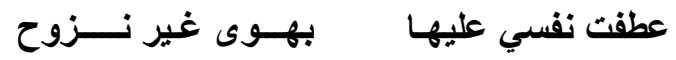

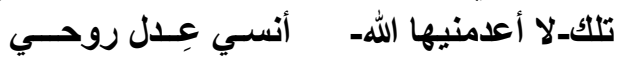

(فاغنر، 1988، صفحة (196)

ولا يطيق الحياة دونها، و لا يفهم لوجوده مغزى مستقلا عن وجودها كما يتجلى فيما يلي:

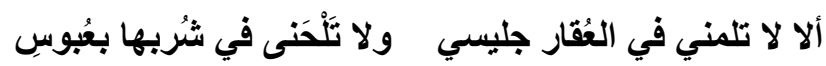

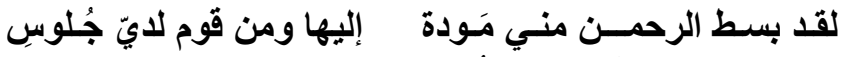

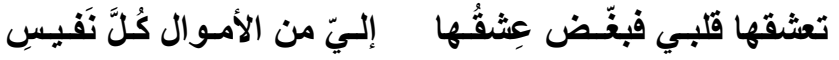

(فاغنر، 1988، صفحة 188)

ومنها قوله:

$$
\text { دع عنك لومي فإن اللوم إغراء وداوني بالتي كانت هي الداء }
$$

وفسر النويهي هذا البيت بأنه وجْدُ للخمر جامح جارف، فهو لا يأبه بلوم الناس ولا يصده عن المحبوب من عيوب ونقائص. هذا الحب الطاغي إن كان يحمل المحب على الأسى واللوعة حين يفكر في محبوبه، فهو يحمله على الغضب والتحدي

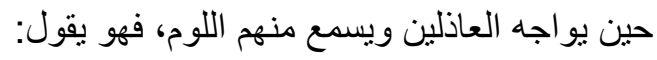

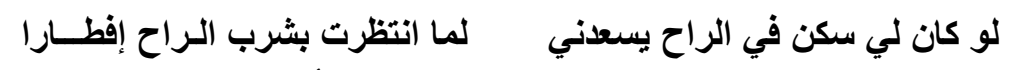

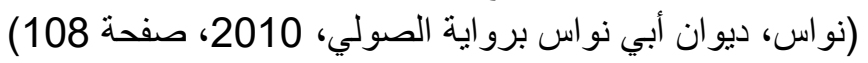

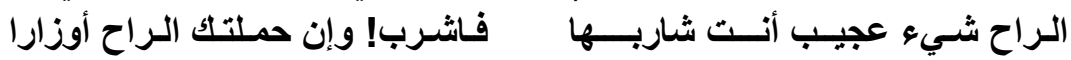

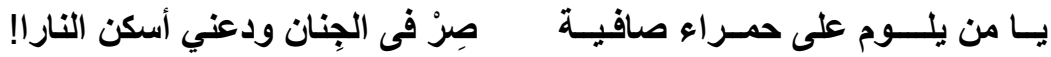

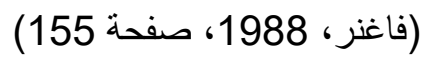

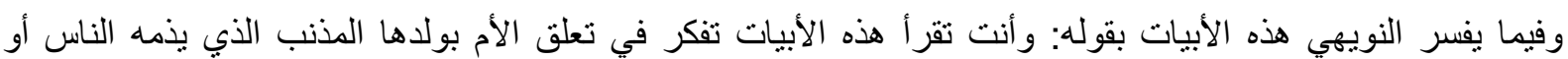

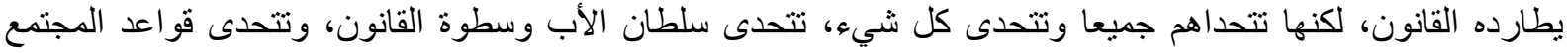

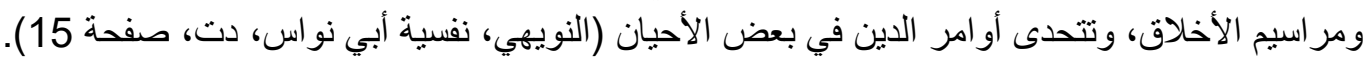
حب أبو نواس للخمر حب إكبار و إجلال أيضا وحب تقديس، ينظر إليها كما لو كانت كائنا عظيما، يقول: 


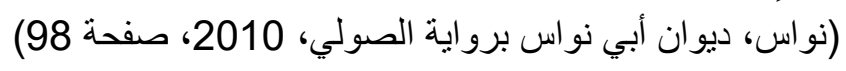

\section{ووقِّر الكأس عن سفيهٍ فِإن آيينها الوقار}

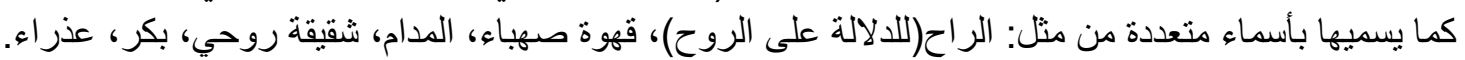

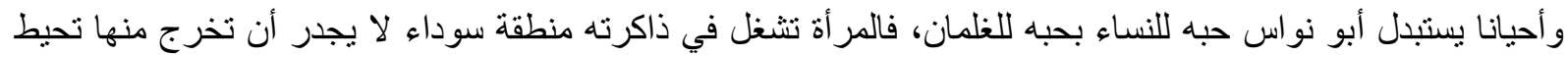

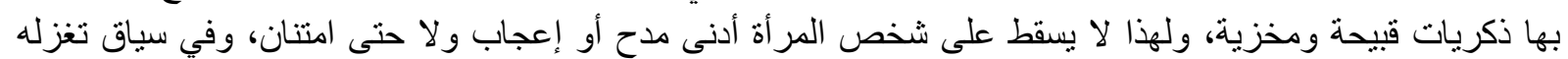

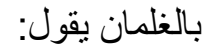

$$
\begin{aligned}
& \text { شبيه بالقضيب وبالكثيب ريب الحسن في قد غريب } \\
& \text { بعيد إن نظرت إليـه يوما }
\end{aligned}
$$

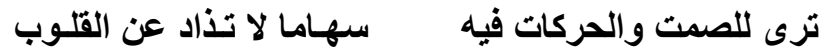

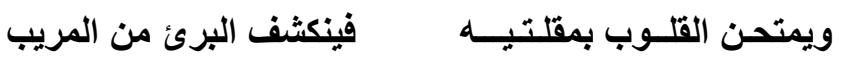

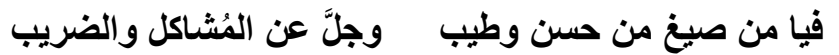

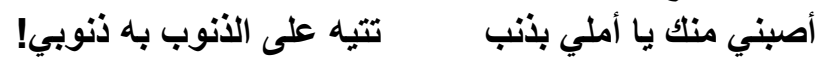

\section{2-2 مفهوم حقيقة التسامي Sublimation}

لا نتخذ فيها الرغبة الجنسية الوسائل المعروفة في الإرضاء، صحيحها وشاذها، بل تسلك مسالك أخرى من النشاط ما كنا

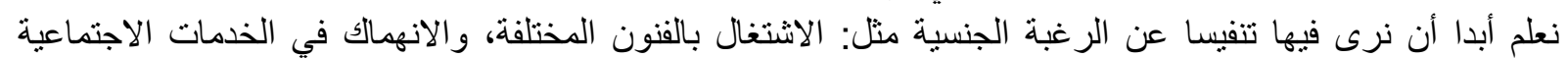

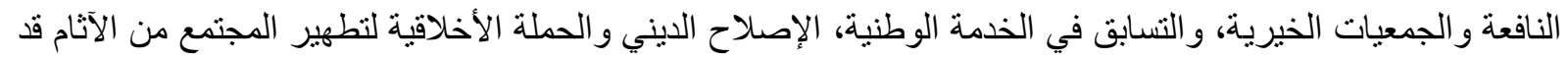

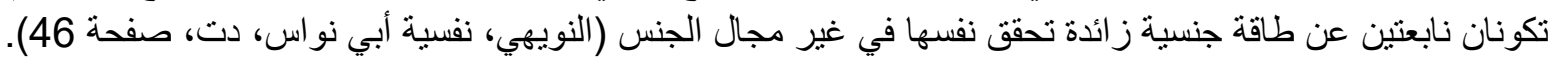

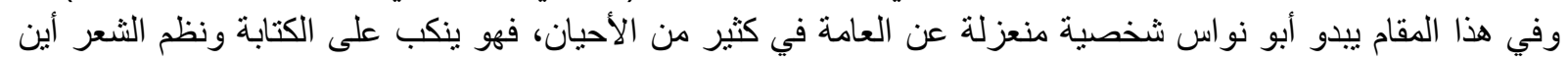

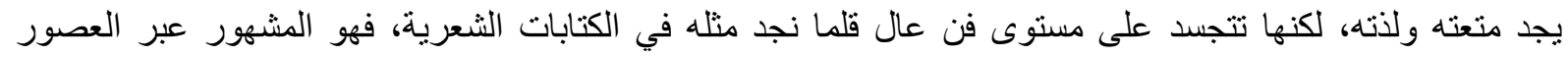

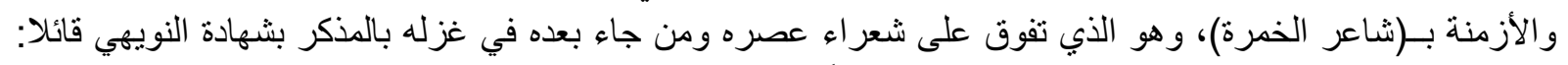

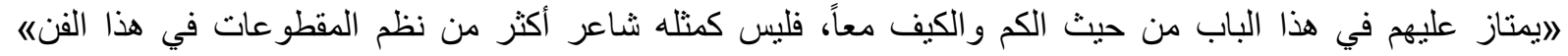

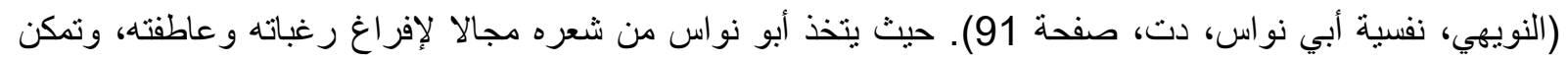

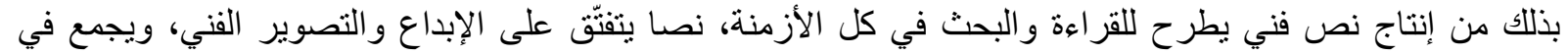

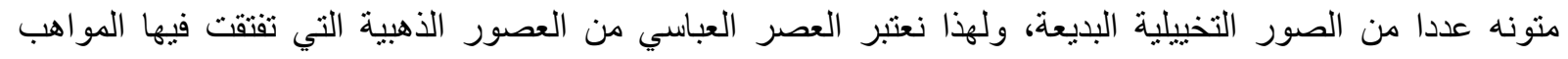

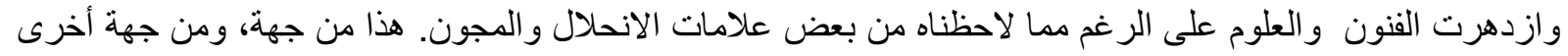

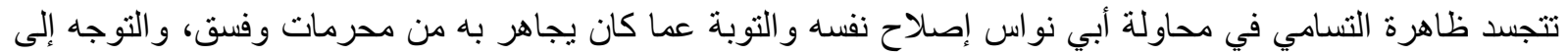

$$
\begin{aligned}
& \text { أنا اكتسبت لنفسي هذا العناء المعنّى }
\end{aligned}
$$

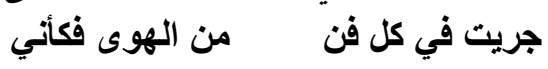

$$
\begin{aligned}
& \text { مما فعلت بنفسي عليّ كنت بضغن فئن }
\end{aligned}
$$

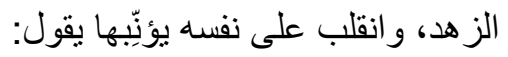

\section{: Phallo-centrisme مفهوم التمركز القضيبي}

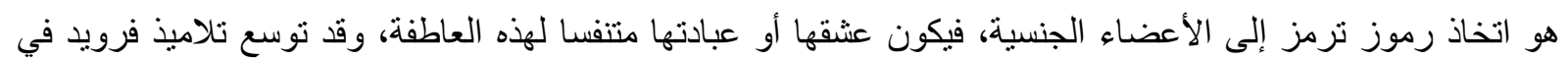

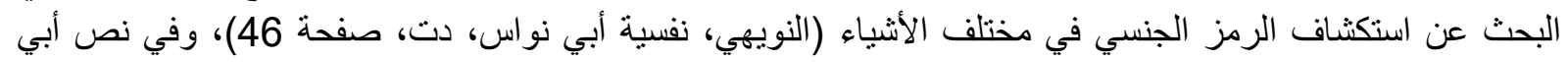

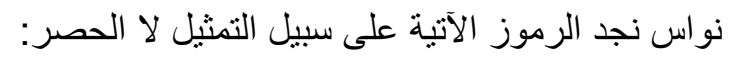
حين يلامس فمه قدحها فيرشف رحيقها بشوق، فئل التها تقبيل شافه عنده، نفس اللذة التي يستشفها من تقبيل فم الأنثى أو خدها،

ترحل عن صدره الههوم إذا قبل فوه بلذة فاها

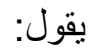

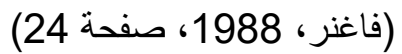

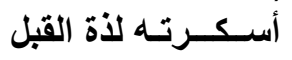

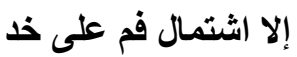

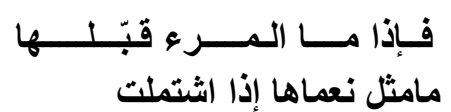


تقبيل بلذة، و هو قبل كثثرة مسكرة، وليس مجرد نلامس بل هو (اشتمال) أي أن شفتيه تحتويانها بنهم و إطالة (النويهي،

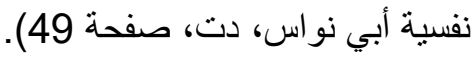
هكذا حلّل النويهي نفسية أبي نواس مُسقِطا بذلك المنهج النفسي على النص النص الأدبي الفني، معتبر ا شخصية الثاعر حالة

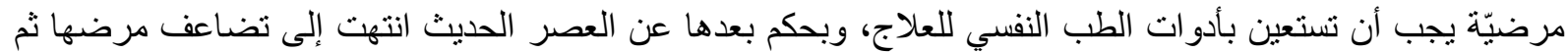
موتها.

الخاتمة:

في خاتمة هذا البحث نحب أن نُنَّهِ بمجمو عة من المآخذ رأيناها في عمل الناقدين، وفيما يلي يأتي التقصيل فيها:

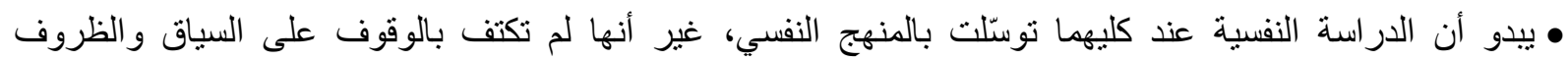

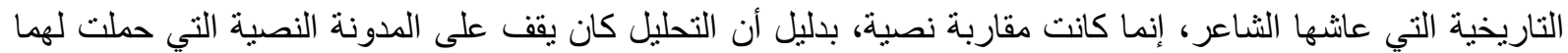

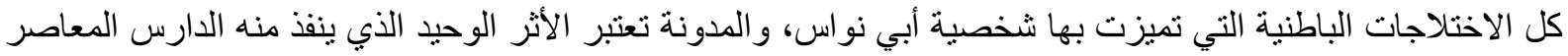

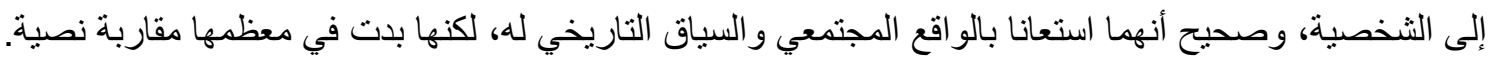

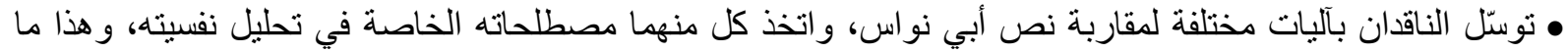

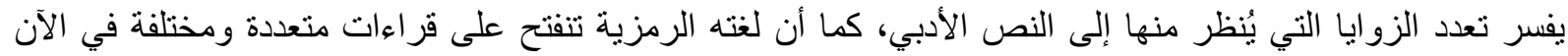

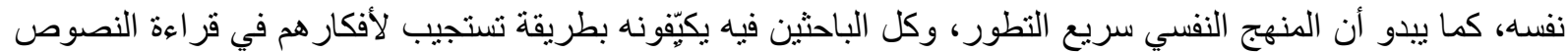

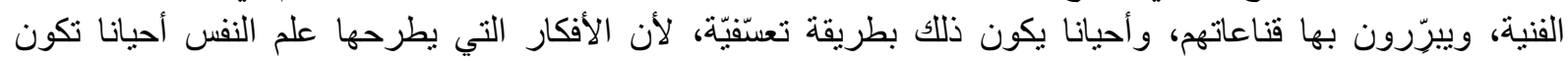

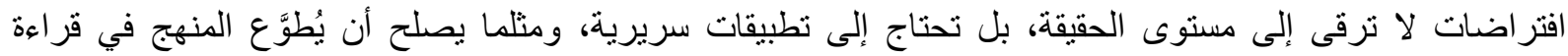

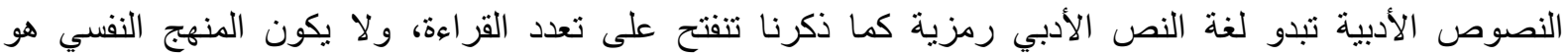

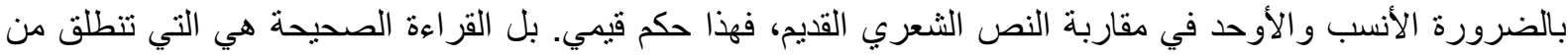

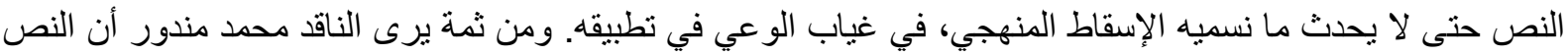

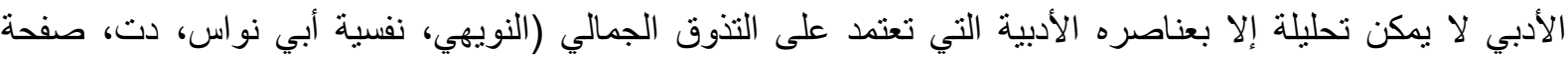

• الثاعر أبو نواس من وجهة نظر العقاد من عباقرة الشعر القيده، شغفه وحبه الكبير للخمر كان مُلهِهًا لله على إنتاجه

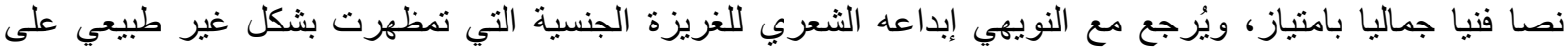

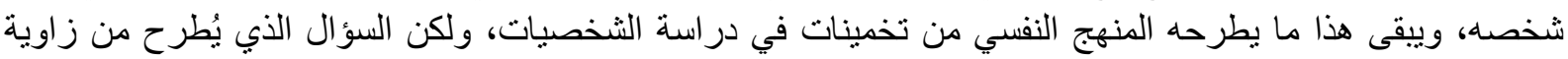
أخرى هو: هل ينبثق الإبداع من الغريزة الجنسية فحسب؟ أليس هناك مصدر آخر لهذا الفن غير نفسه الباطنة؟ الالا يحظى الإنى

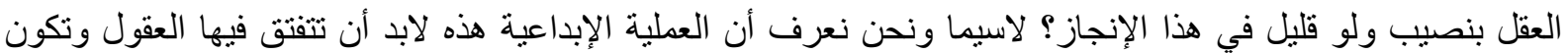

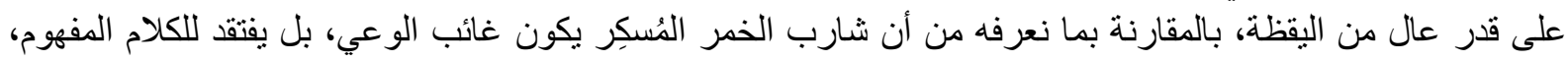

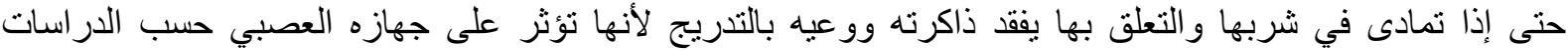
العلمية المتأخرة. ومن ثمة يبقى النص النواسي مطروحا لدر اسات قد تكشف لنا لنا عن جوانب أخرى أغفلها التها التحليل النفسي.

قائمة المصادر والمراجع

أبو نو اس، تح بهجت عبد الغفور الحديثي. (2010). ديو ان أبي نواس برواية الصولي. أبو ظبي: دار الكتب الوطنية.

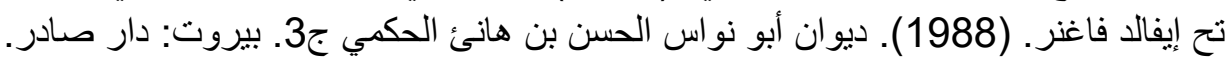

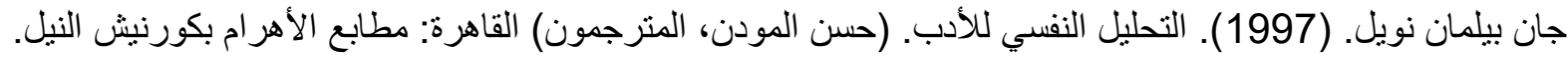

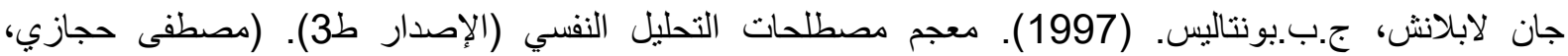

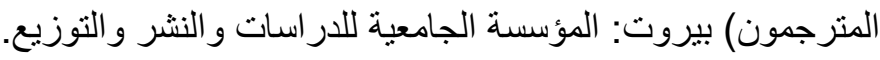

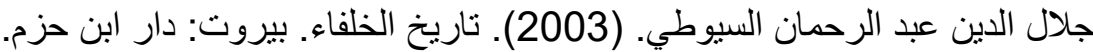

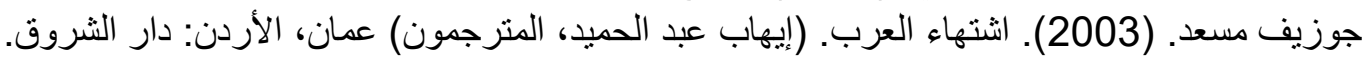

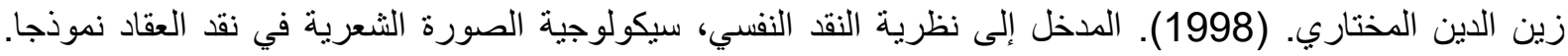

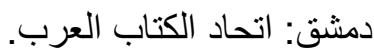

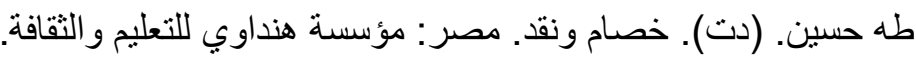

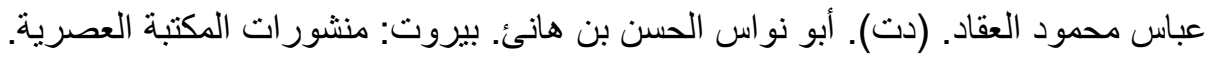


عباس محمود العقاد. (دت). عبقرية عمر . مصر : مؤسسة هنداوي للتعليم و الثقافة.

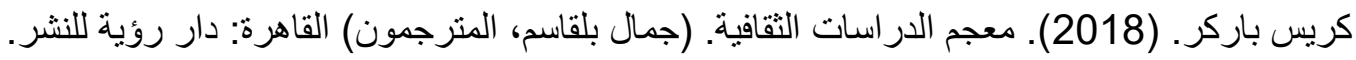

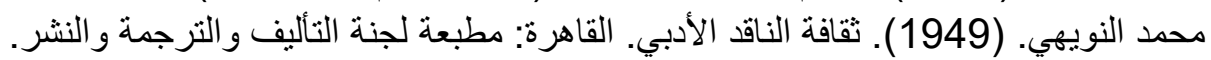

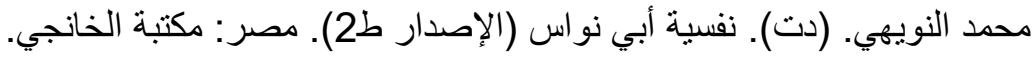
مصطفى هدارة. (1963). اتجاهات الثعر العربي في القرن الثاني للهجري. بيروت: دالئ دار المعارف. 